\title{
Corrigendum: Barriers, Benefits, and Beliefs of Brain Training Smartphone Apps: An Internet Survey of Younger US Consumers
}

\author{
John Torous ${ }^{1 *}$, Patrick Staples ${ }^{2}$, Elizabeth Fenstermacher ${ }^{1}$, Jason Dean ${ }^{1}$ and \\ Matcheri Keshavan ${ }^{1}$ \\ ${ }^{1}$ Department of Psychiatry, Beth Israel Deaconess Medical Center, Boston, MA, USA, ${ }^{2}$ Department of Biostatistics, Harvard \\ T.H. Chan School of Public Health, Boston, MA, USA
}

Keywords: brain, apps, smartphones, memory, technology assessment

\section{A corrigendum on}

Barriers, Benefits, and Beliefs of Brain Training Smartphone Apps: An Internet Survey of Younger US Consumers

by Torous, J., Staples, P., Fenstermacher, E., Dean, J., and Keshavan, M. (2016). Front. Hum. Neurosci. 10:180. doi: 10.3389/fnhum.2016.00180

OPEN ACCESS

Edited and reviewed by:

Soledad Ballesteros,

Universidad Nacional de Educación a

Distancia, Spain

*Correspondence: John Torous

jtorous@bidmc.harvard.edu

Received: 02 May 2016 Accepted: 17 May 2016 Published: 02 June 2016

Citation: Torous J, Staples P, Fenstermacher E,

Dean J and Keshavan M (2016) Corrigendum: Barriers, Benefits, and Beliefs of Brain Training Smartphone Apps: An Internet Survey of Younger US Consumers.

Front. Hum. Neurosci. 10:253. doi: 10.3389/fnhum.2016.00253
Reason for Corrigendum: Addition of conflict of interest statement by Dr. Matcheri Keshavam. Clearly state the mistake being fixed.

After publication, Dr. Matcheri Keshavan noted the paper should include this statement "MK has a contract to purchase Lumosity services for one of his studies, and has provided consultant services to Forum Pharmaceuticals."

\section{AUTHOR CONTRIBUTIONS}

JT and MK conceived the research idea. JT, EF, and JD wrote the protocol and IRB. PS analyzed the data and produced all figures. JT, EF, JD, and MK conducted background literature review. All authors helped in the writing and drafting on this manuscript. All authors edited the manuscript.

Conflict of Interest Statement: The authors declare that the research was conducted in the absence of any commercial or financial relationships that could be construed as a potential conflict of interest.

MK has a contract to purchase Lumosity services for one of his studies, and has provided consultant services to Forum Pharmaceuticals.

Copyright () 2016 Torous, Staples, Fenstermacher, Dean and Keshavan. This is an open-access article distributed under the terms of the Creative Commons Attribution License (CC BY). The use, distribution or reproduction in other forums is permitted, provided the original author(s) or licensor are credited and that the original publication in this journal is cited, in accordance with accepted academic practice. No use, distribution or reproduction is permitted which does not comply with these terms. 